\title{
Near-Stoichiometric Adsorption of Phosphate by Silica Gel Supported Nanosized Hematite
}

\author{
L. I. Gromadskaya, ${ }^{1}$ I. V. Romanova, ${ }^{1}$ O. A. Vyshnevskyi, ${ }^{2}$ and S. A. Kirillov ${ }^{1,3}$ \\ ${ }^{1}$ Institute for Sorption and Problems of Endoecology, 13 General Naumov Street, 03164 Kyiv, Ukraine \\ ${ }^{2}$ Institute of Geochemistry, Mineralogy and Ore Formation, 34 Palladin Prospect, 03142 Kyiv, Ukraine \\ ${ }^{3}$ Joint Department of Electrochemical Energy Systems, 38A Vernadsky Avenue, 03142 Kyiv, Ukraine
}

Correspondence should be addressed to S. A. Kirillov; kir@i.kiev.ua

Received 3 June 2013; Accepted 20 June 2013

Academic Editors: A. M. Fonseca and Y. Wei

Copyright (C) 2013 L. I. Gromadskaya et al. This is an open access article distributed under the Creative Commons Attribution License, which permits unrestricted use, distribution, and reproduction in any medium, provided the original work is properly cited.

\begin{abstract}
Decreasing the size of oxide particles to nanoscale enables one to ensure maximal reaction rates and depths in the solid due to the enhancement of the specific surface area and the increase of the diffusion rate caused by shortening diffusion paths. For that reason, one may suggest that in the case of adsorption onto nanoparticles, the complete conversion of sorbents to stoichiometric compounds would become possible. Adsorption of phosphate ions onto nanosized hematite supported on silica gel surface has been studied. Modification of silica gel surface by hematite in the quantity of 0.62 and 1.25 mass $\%$ has been carried out by means of a citric acid aided method. The morphology of the samples obtained has been characterized using DTA, XRD, SEM, and low temperature desorption of nitrogen. It has been found in batch experiments that unlike natural and synthetic hematites, for which the limiting adsorption values do not exceed $14 \mathrm{mg} / \mathrm{g}$, silica gel supported nanosized hematite adsorbs $400-2000 \mathrm{mg}$ of the phosphate ions per gram, thus forming near-stoichiometric iron phosphates on the surface of the support. The degree of conversion of hematite to iron phosphates is greater in acidic media and at a lower surface coverage, when hematite crystallites are small and better accessible by adsorbate.
\end{abstract}

\section{Introduction}

Numerous metal oxides are capable of absorbing inorganic and organic contaminants and due to this ability they are widely used as scavengers of toxic impurities. Advances in nanoscale science and engineering have raised hopes that many of the current problems involving water quality could be resolved or greatly ameliorated using nanosorbents, nanocatalysts, nanostructured catalytic membranes, and nanoparticle-enhanced filtration techniques resulting from the development of nanotechnology [1]. Decreasing the size of oxide particles to nanoscale enables one to ensure maximal reaction rates and depths in the solid due to the enhancement of the specific surface area and the increase of the diffusion rate caused by shortening diffusion paths $[1,2]$. For that reason, one may suggest that in the case of adsorption onto nanoparticles, the complete conversion of sorbents to stoichiometric compounds would become possible. However, in spite of these striking benefits, the direct application of nanosized oxides in dynamic sorption is out of question in view of enormous hydraulic resistances of nanopowders. Therefore, studies in the field of nanoadsorptives can be divided into two major areas. The first area includes the works describing potentialities of nanoparticles themselves and the second deals mainly with nanocomposites.

In the first area, better understanding of physicochemical aspects of adsorption on oxide nanoparticles, as well as their impact on the fate of environmental pollutants that adsorb onto them in aqueous and biologically relevant media has been achieved in batch studies [3]. In particular, dependences of sorption on grain size have been obtained for a few materials, including iron oxides [4-7], titania [8-12], and clay 
minerals $[13,14]$. With a few exceptions $[7,8,10]$, a conclusion has been drawn that the adsorption affinity increases as the particle size decreases.

In the second area, significant efforts are directed towards the synthesis of composites where nanosized adsorbents are either incorporated into a polymeric matrix $[15,16]$ or deposited onto the surface of a support [17]. Such composites are prospective for practical applications in fixedbed process units or in flow-through systems like permeable barriers [18]. Much works in this field deal with iron oxides especially active towards phosphorus and arsenic compounds containing in aqueous media [19]. These compounds are notorious toxicants, and their presence in drinking water at concentrations exceeding certain (quite low) limits produces numerous diseases [17, 19-21]. As supports for nanosized iron oxides, polymers $[22,23]$ and inorganic substances, for example, sand [24], concrete [25], or activated carbon [26] are used and high uptakes of phosphates and arsenates are attained.

According to batch studies mentioned above, no evidences regarding the complete conversion of sorbents to stoichiometric compounds have been obtained yet. In order to prove the possibility of such phenomenon, a combination of approaches peculiar to both areas of nanoadsorptive studies seems favorable. Potentialities of nanoparticles in adsorption processes are largely obscured by phenomena like aggregation and agglomeration of nanopowders, precipitates, or sediments probed in batch experiments [4-14]. Deposition of small amounts of nanoadsorbents onto the surface of a support could be helpful in avoiding this complication.

Silica could be a prospective support for various oxides. Mechanical stability, great specific surface area, and high reaction ability of silanol $(\equiv \mathrm{Si}-\mathrm{O}-\mathrm{H})$ groups allowing for surface modification are usually put forward as advantages of this support [28]. Surface modification by organic or inorganic substances as well as by metal complexes enriches silica with high hydrolytic and thermal stability and enhances its adsorption selectivity towards atypical ions [29-31].

In this paper, our primary aim was to examine the ability of nanosized iron oxide to the complete conversion to stoichiometric iron phosphates in the course of adsorption from aqueous solutions. To do so, we performed an attempt to deposit a nanolayer of iron oxide onto the surface of a commercial silica gel. Owing to silanol groups, silica demonstrates mainly cation exchange function, and the absence of anion exchange ability of silica is especially advantageous for studies of modifiers demonstrating their anion exchange function (like iron oxides), since concurring adsorption of anions onto the support is of no value in this case. In order to perform surface modification of silica, instead of more common and sometimes more difficult methods (treatment by metal alkoxides in water-free organic solvents and subsequent calcination $[32,33]$ and impregnation by solutions of metal salts [33]), we used a citric acid aided route already employed in our papers [34-37] for obtaining nanosized metal oxides. We supposed that an acidic citrate compound [35-37] formed by a reaction between an iron salt and citric acid should be bound to silanol groups and after a thermal treatment should produce one of the iron oxides. It was found that in our case, the oxide in question was $\mathrm{Fe}_{2} \mathrm{O}_{3}$ (hematite). Modified silica gel samples were tested as sorbents for phosphate ions from solutions of various acidities. It appeared that, as expected, the hematite layer deposited onto the silica gel surface can be almost completely converted to iron phosphates.

\section{Materials and Methods}

Granulated fine-pored technical silica gel (KSMG, GOST 3956-76 [38], Makrokhim, Ukraine) was used as a support. Samples were washed and dried during $2 \mathrm{~h}$ at $120^{\circ} \mathrm{C}$ and $2 \mathrm{~h}$ at $210^{\circ} \mathrm{C}$; their specific surface area was determined as $480 \mathrm{~m}^{2} / \mathrm{g}$. Since according to data sheets [38] fine-pored technical silica gels may contain admixtures of other oxides, first of all, alumina, the chemical analyses of the support for aluminum and iron content were performed according to the existing standards [39-41]. It should be mentioned that procedures described in these standards practically coincide with those recommended by ASTM [42]. In particular, the analysis of the support was made according to [39-41] by means of back complexometric titration after dissolution of samples in a mixture of sulfuric and hydrofluoric acids. It showed the absence of ferric oxide and the presence of $5.0 \%$ of aluminum oxide.

The initial modifier solution contained equimolar amounts of ferric chloride $\mathrm{FeCl}_{3} \cdot 6 \mathrm{H}_{2} \mathrm{O}$ and citric acid ( $\mathrm{p}$. a., no additional purification). Based on the studies of adsorption of $\mathrm{Fe}^{3+}$ ions on silica gel (see below), the concentrations of $\mathrm{Fe}^{3+}$ in working modifier solutions were set to $1.26 \mathrm{~g} / \mathrm{L}(0.023 \mathrm{~mol} / \mathrm{L})$ and $14 \mathrm{~g} / \mathrm{L}(0.25 \mathrm{~mol} / \mathrm{L})$ and adjusted by dilution. The impregnation of silica gel was made by means of $4 \mathrm{~h}$ shaking and $24 \mathrm{~h}$ of static contact; solid : liquid $=1: 100$.

In order to find the decomposition temperature of ferric citrate formed in the modifier solution, which determines the conditions of the thermal treatment of impregnated silica gel samples, this salt was synthesized accordingly [3537]. Specifically, the modifier solution was evaporated at 80-90 ${ }^{\circ} \mathrm{C}$ until a viscous dark-brown resin was formed and left overnight. Heating the resin at ca. $120^{\circ} \mathrm{C}$ gave an acidic citrate (precursor). Its decomposition was studied by means of thermal analysis (Q-1500, MOM, Hungary) and X-ray diffractometry (DRON UM-1, LOMO, Russia, Co-K $\mathrm{K}_{\alpha}, \lambda=$ $1,79283 \AA$ ).

Specific surface areas and pore size distributions for initial and modified silica gels were obtained from nitrogen adsorption/desorption curves (NOVA 2200e, Quantachrome, USA). A Nova Win 2.0 software was employed for calculations. Specific surface areas and total pore volumes were found using the BET method. To acquire the volume of mesopores and micropores, BJH and DFT methods, respectively, were utilized. The morphology of the modified samples was studied by means of scanning electron microscopy (JSM-6700F, JEOL, Japan).

The amount of ferric compound on the surface of silica gel (ferric citrate in the case of impregnation of silica gel or ferric oxide in the case of modified silica gel samples) was determined by means of a colorimetric procedure with 
o-phenantroline [43] after the alkaline fusion of samples (a KFK-2 colorimeter, UKL, Russia).

pH titrations by $\mathrm{NaOH}$ and $\mathrm{HCl}$ (I-160 M, IT, Belorus) were performed in $0.1 \mathrm{M}$ background solutions of sodium chloride (solid:liquid $=1: 100) 4 \mathrm{~h}$ shaking and one day of static contact. Sorption studies were performed in batch experiments. Sorption of ferric citrate from the modifier solution was examined by the amount of ferric oxide on silica gel. Sorption of phosphate ions was determined using solutions of $\mathrm{Na}_{2} \mathrm{HPO}_{4} \cdot 2 \mathrm{H}_{2} \mathrm{O}$ as a source of phosphate ions. Proper $\mathrm{pH}$ values were maintained by means of $\mathrm{HCl}$ solutions. In these studies, $1 \mathrm{~g}$ of the sorbent was added to $10 \mathrm{~mL}$ of solution. This gives the solid: liquid ratio of $1: 10$ and the ratio of the mass of ferric oxide on the surface of the sorbent to the volume of solution of $1: 161$ for sample $A$ and 1:80 for sample B (see later). Resulting mixtures were shacked for $4 \mathrm{~h}$, and left for 1 day, after which the sorbents were removed by means of filtration and the phosphate content in filtrates was determined colorimetrically by the vanadium phosphomolybdate (vanadate colorimetry method) [44]. The adsorption capacity values $A(\mathrm{mg} / \mathrm{g})$ were calculated as

$$
A=\frac{\left(C_{0}-C_{\text {eq. }}\right) \times V \times 1000}{m},
$$

where $C_{0}$ and $C_{\text {eq. }}$ are the concentrations of the adsorbate in $\mathrm{mg} / \mathrm{L}$ in initial and equilibrium solutions, respectively, $V$ is the volume of the solution in $\mathrm{mL}$, and $m$ is the mass of the sorbent in $\mathrm{g}$.

\section{Results and Discussion}

In order to deposit a prescribed amount of the modifier onto the surface of the support, the study of adsorption of $\mathrm{Fe}^{3+}$ ions on silica gel from modifying solutions was performed. The data obtained are shown in Figure 1. Respective concentrations of working modifying solutions chosen for further experiments are denoted by arrows. It was expected that using the modifying solutions containing 1.26 and $14 \mathrm{~g} / \mathrm{L}$ of Fe ${ }^{3+}$ one should obtain the samples containing such amounts of iron oxide on the surface that differ approximately twice.

As another preliminary stage of the work, a single iron oxide was obtained by means of the citric acid method mentioned above, and its identification was performed. The minimal temperature required for the thermal decomposition of the precursor was determined by means of the thermal analysis. Precursors of other oxides demonstrate several stages of thermal decomposition including endothermic removal of physisorbed and hydrate water and exothermic crystallization of a citrate salt, both occurring in the region of $100-150^{\circ} \mathrm{C}$, and exothermic decomposition (burning up) of the acid radical and formation of a target oxide taking place at $250-400^{\circ} \mathrm{C}$ [35-37]. In the case of the precursor studied, two first thermal effects are weak and hardly distinguishable resulting in the DTA curve dominated by a strong exothermic effect $\left(250-400^{\circ} \mathrm{C}\right)$ corresponding to the burning process. After this effect, formation of an iron oxide is completed and no additional mass losses take place.

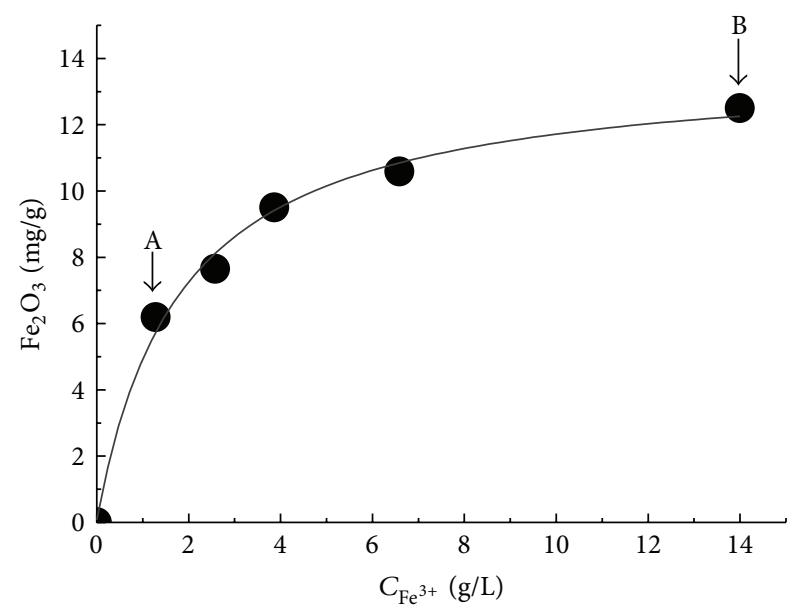

FIGURE 1: Dependence of adsorption of $\mathrm{Fe}^{3+}$ onto initial silica gel on its concentration in modifying solution. Arrows show the concentrations of working modifying solution chosen for further experiments.

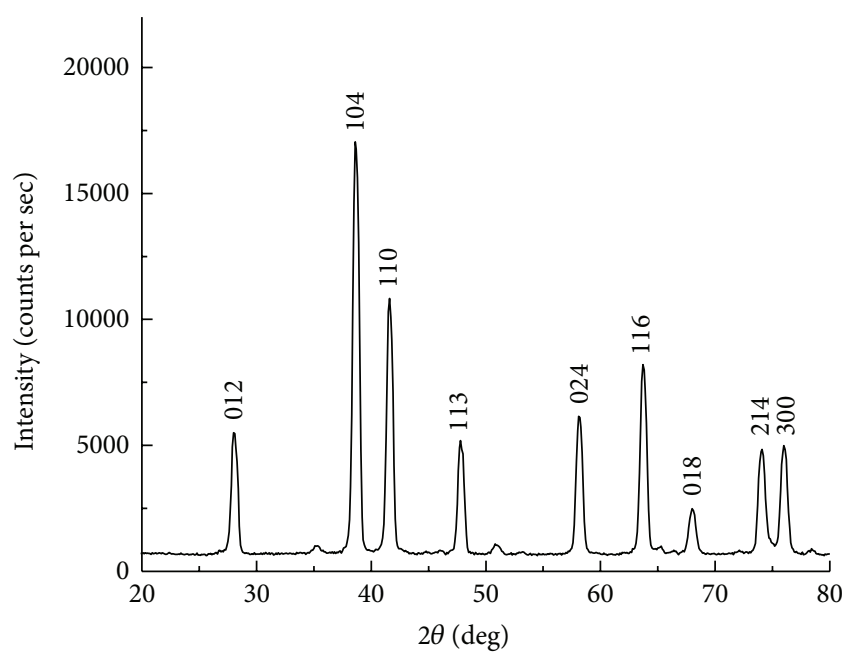

Figure 2: X-ray diffraction data for iron oxide obtained by the treatment of the citrate precursor at $400^{\circ} \mathrm{C}$ for $1 \mathrm{~h}$.

As the decomposition products, several iron oxides should be considered, namely, magnetite $\mathrm{Fe}_{3} \mathrm{O}_{4}$, maghemite $\gamma$ - $\mathrm{Fe}_{2} \mathrm{O}_{3}$, and hematite $\alpha-\mathrm{Fe}_{2} \mathrm{O}_{3}$. Furthermore, it should be taken into account that massive samples of maghemite are fully transformed into hematite at $\sim 500^{\circ} \mathrm{C}[45]$. On the other hand, hematite is stable if its grain size exceeds $30 \mathrm{~nm}$ and transforms to maghemite upon subdivision [46].

In order to distinguish between possible varieties of iron oxides formed upon the thermal decomposition of citrate precursors, a sample treated at $400^{\circ} \mathrm{C}$ for $1 \mathrm{~h}$ was analyzed by means of X-ray diffractometry. Its diffraction pattern (Figure 2) contains the peaks characteristic of hematite (JCPDS 16-0895). This means that the decomposition reaction leads to the formation of hematite having the grain size of $>30 \mathrm{~nm}$. Calculations using the Scherrer equation [47] support this statement leading to the size of crystallites of $50 \mathrm{~nm}$. 
TABLE 1: Porosity data for initial and modified silica gels.

\begin{tabular}{|c|c|c|c|c|c|c|c|}
\hline Sample & $\begin{array}{l}S_{\text {sp. }}{ }^{1} \\
\mathrm{~m}^{2} / \mathrm{g}\end{array}$ & $\begin{array}{l}V_{\text {total }}, \\
\mathrm{cm}^{3} / \mathrm{g}\end{array}$ & $\begin{array}{l}V_{\text {meso }}^{2} \\
\mathrm{~cm}^{3} / \mathrm{g}\end{array}$ & $\begin{array}{c}V_{\text {micro }}^{1,2} \\
\mathrm{~cm}^{3} / \mathrm{g}\end{array}$ & $\begin{array}{c}\text { Micropore } \\
\text { fraction, } \\
V_{\text {micro }} / V_{\text {total }} \text {, } \\
\%\end{array}$ & $\begin{array}{c}r_{\text {mean }}^{1}, \\
\mathrm{~nm}\end{array}$ & $\begin{array}{c}r_{\mathrm{BJH}}{ }^{2}, \\
\mathrm{~nm}\end{array}$ \\
\hline Initial & 480 & 0.403 & 0.380 & 0.023 & 5.7 & 1.68 & 1.77 \\
\hline A & 484 & 0.393 & 0.368 & 0.025 & 6.36 & 1.62 & 1.66 \\
\hline B & 536 & 0.420 & 0.229 & 0.190 & 45.5 & 1.57 & 1.72 \\
\hline
\end{tabular}

${ }^{1}$ By BET.

${ }^{2}$ By BJH.

After these preliminary works, two samples of silica gel impregnated in modifying solutions of different concentrations were obtained, pretreated, and calcined for $1 \mathrm{~h}$ at $400^{\circ} \mathrm{C}$, as in the case of single iron oxide obtained from the citrate precursor. These samples of modified silica gel were denoted as $\mathrm{A}$ and $\mathrm{B}$. Their alkaline fusion and subsequent analysis show the amount of $\mathrm{Fe}_{2} \mathrm{O}_{3}$ as $6.2 \mathrm{mg} / \mathrm{g}$ for the A sample and $12.5 \mathrm{mg} / \mathrm{g}$ for the $\mathrm{B}$ sample, respectively.

The results of porosity studies of the initial sample and sample B (for samples A and B these are almost the same) are presented in Figure 3 as isotherms of nitrogen adsorption/desorption (a) and pore size distributions (b) and summarized in Table 1 . These isotherms are characteristic of silica gels and, according to the IUPAC classification [27], belong to the IV type and have $\mathrm{H} 2$ type hysteresis loops. For sample $\mathrm{B}$, the isotherms are situated higher than those for the initial sample thus indicating greater pore volume. Specific surface areas for modified samples are greater than those for the initial sample. Upon modification, the total pore volume increases, whereas the mean pore radii are not changing significantly.

Analyzing the pore size distributions calculated according to the BET and $\mathrm{BJH}$ methods (Table 1), it was found that in all samples, mesopores of approx. $1.7 \mathrm{~nm}$ radii prevail, and modification decreases their volume $\left(V_{\text {meso }}\right)$. For sample $\mathrm{B}$, such a decrease amounts at ca. 25\%. At the same time, both the specific surface area $S_{\mathrm{sp}}$. and the total pore volume $V_{\text {total }}$ found according to the BET procedure either remain almost unchanged (sample A) or increase (sample B). To explain this conflicting result based on calculations in terms of the BET and $\mathrm{BJH}$ methods, a hypothesis was put forward regarding the presence of micropores in modified samples (their amount can be estimated as $V_{\text {total }}-V_{\text {meso }}=V_{\text {micro }}$ ) and the data of other pore size calculation methods were applied. In fact, data treatment in terms of microporosity sensitive $t, \mathrm{DR}$, and DFT methods reveals the presence of micropores in the samples studied. A representative pore size distribution curve obtained using the DFT method is given in Figure 3(b) demonstrating that modification leads to a decrease of the number of big pores and appearance of small pores of 0.5 and $1.25 \mathrm{~nm}$ radii. Since this feature is more characteristic of the sample B containing a greater amount of iron oxide on the surface, one can suggest that the oxide layer deposited onto the silica gel surface is not uniform and possesses cracks and micropores [48].

Knowing the amount of iron oxide deposited onto silica gel and being based on the porosity data, one can speculate

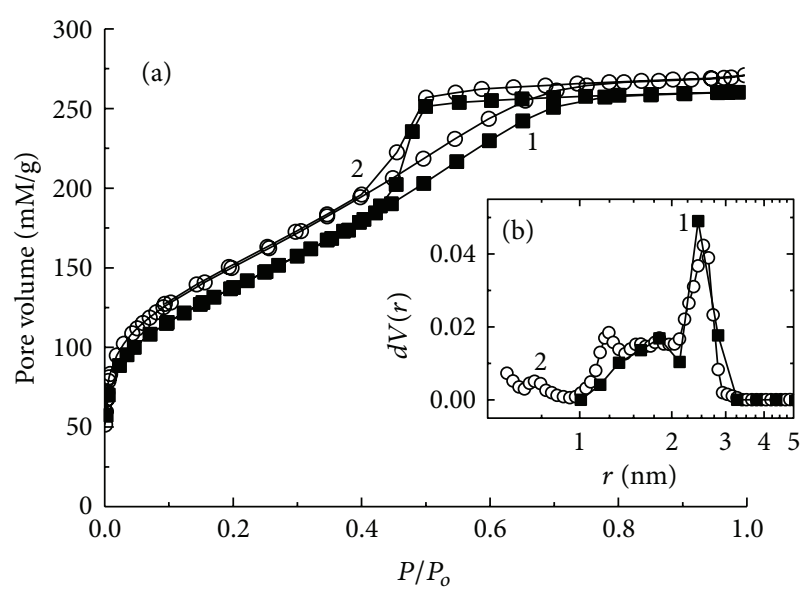

FIGURE 3: Nitrogen adsorption/desorption isotherms (a) and pore size distributions obtained in terms of the DFT method for initial (1) and modified (2) silica gels.

regarding the degree of coverage of the surface. Consider sample B for clarity. Hexagonal crystals of hematite belong to the $D_{3 d}^{6}-R \overline{3} c$ space group, $Z=6, a=0.504 \mathrm{~nm}, c=1.377 \mathrm{~nm}$ [49], and their density is $5.25 \mathrm{~g} / \mathrm{cm}^{3}$. If the crystals are set up on their basal planes (the $c$ axis is directed upwards), a monocrystalline layer of hematite of $12.5 \mathrm{mg}$ mass will occupy the area of $1.73 \mathrm{~m}^{2}$. This is clearly insufficient for the complete coverage of the surface of support. Furthermore, covering the surface of the pores of silica gel $\left(r_{\text {mean }} \approx 1.7 \mathrm{~nm}\right)$ with a crystalline monolayer of iron oxide of $1.377 \mathrm{~nm}$ thickness will lead to their complete filling and disappearance, which does not hold. Therefore, one can consider that iron oxide covers just the apparent surface of the spherical granules of silica gel, whose size is $\sim 5 \cdot 10^{-4} \mathrm{~m}^{2} / \mathrm{g}$, and the thickness of such a solid coverage cannot exceed $4.76 \mathrm{mkm}$, or 3500 monocrystalline layers of the oxide. It has been mentioned earlier that for such dimensions, the stable phase of iron oxide is hematite. Similar conclusions are applicable for sample A where the mass of hematite and the thickness of the coverage is twice smaller.

This conclusion agrees with the literature data regarding the composition of iron oxide phases existing on modified silica. Let us say that X-ray diffraction patterns of thermally treated samples obtained by sol-gel coprecipitation of mixtures of tetraethoxysilane and ferric chloride (30 mass\%) up to $600^{\circ} \mathrm{C}$ are blank, and only heating at $900^{\circ} \mathrm{C}$ gives evidence of diffraction peaks corresponding to hematite [50]. Fumed 


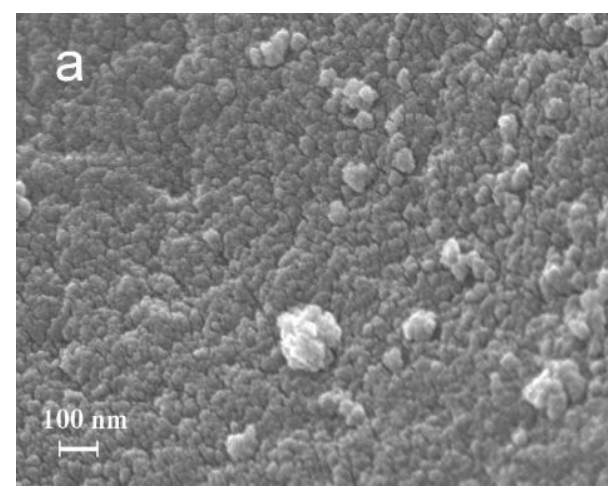

(a)

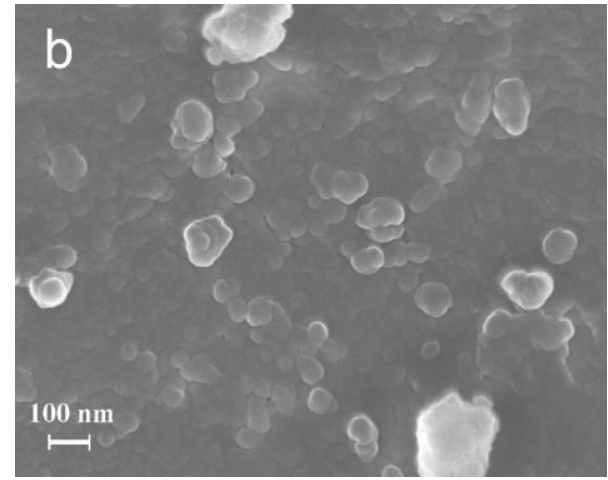

(b)

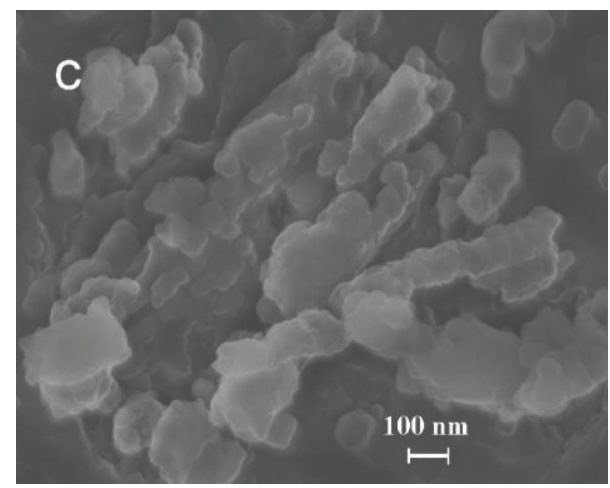

(c)

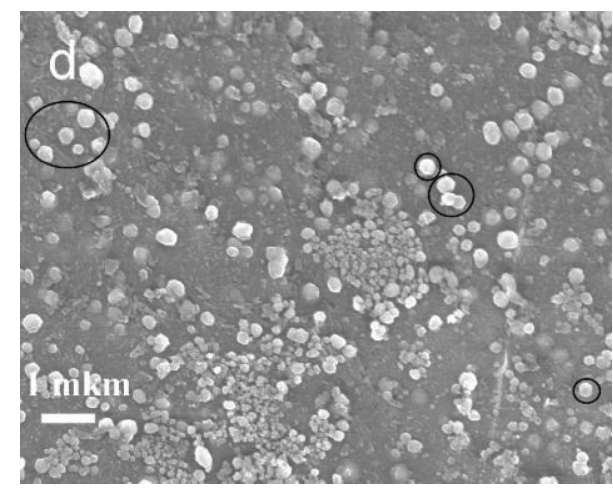

(d)

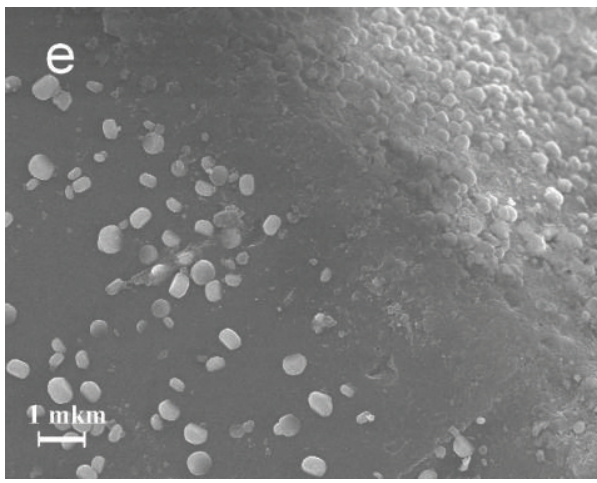

(e)

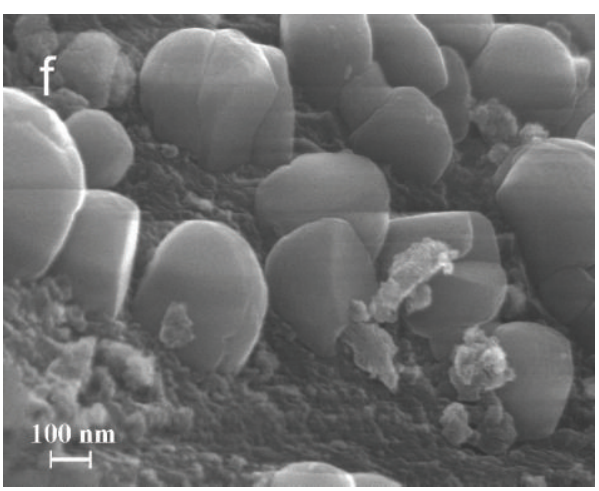

(f)

FIGURE 4: SEM micrographs. Support (a) and sample A at 60000 times magnifications ((b) and (c)) and sample B at various magnifications $((d)-(f))$.

silica impregnated with ferric acetylacetonate and thermally treated at $300^{\circ} \mathrm{C}$ (the total amount of iron oxides in target products varies from 7 to 70 mass\%) contains crystalline phases of maghemite and magnetite. Heating at $600^{\circ} \mathrm{C}$ reveals the presence of hematite, and its fraction grows on rising temperature [32].

In Figure 4, SEM micrographs of the support and samples $A$ and $B$ are shown. These manifest clear difference in morphologies of noncoated and coated silica gels. It is well seen at 60000 times magnification that the bare silica gel exhibits a characteristic structure of the surface (Figure 4(a)), whereas in sample $A$, this structure is not seen due to the presence of coating (Figures 4(b) and 4(c)). Two different kinds of particles forming this coating are discernible. Some of them are of an indefinite shape and the size of approximately $100 \mathrm{~nm}$ (Figure 4(b)). In other regions of the surface (Figure 4(c)), aggregates of flat particles are observed.

In the case of sample $\mathrm{B}$, coating becomes even more evident. It is seen at 10000 times magnification that the oxide layer is not homogeneous and contains separated crystals having the hexagonal habit characteristic of hematite [51] (representative examples of clearly hexagonal single crystals are denoted in Figure 4(c) by circles) and the islands of a crystalline crust. Investigations of chippings at 7000 times magnification demonstrate that big crystals can germinate from the thin crust of the iron oxide (Figure 4(d), right upper 


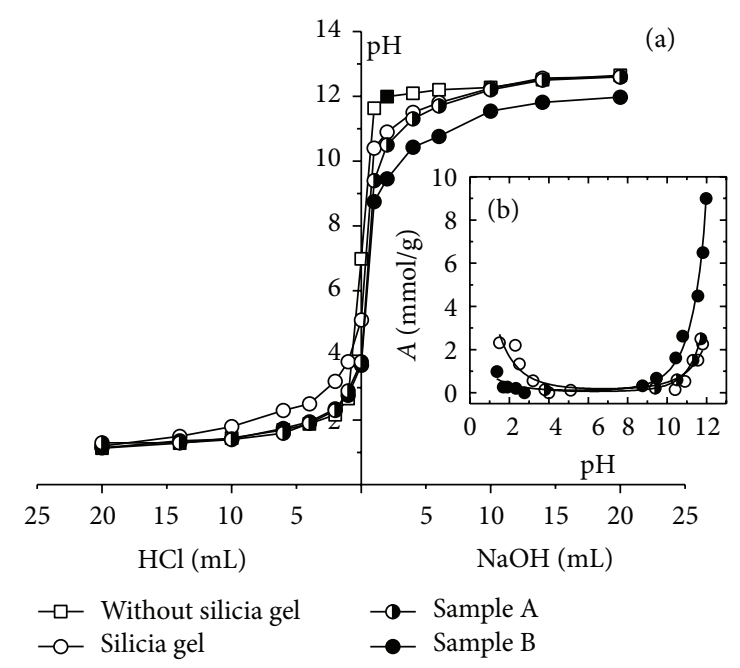

FIGURE 5: $\mathrm{pH}$ titrations (a) and dependence of adsorption capacity (b) on $\mathrm{pH}$ for initial silica gel and modified samples.

corner, the light-colored part of image). Upon cracking the sample, some of bigger crystals are falling down and adhere to the chippings (right lower corner, light-colored grains against a dark background). Studies at 60000 times magnification (Figure 4(f), cf. with the micrographs of the support and sample A presented in Figure 4 at the same magnification) enable one to measure the size of the big crystals (up to $800 \mathrm{~nm}$ height and $400 \mathrm{~nm}$ thickness) and to estimate the width of the crystals forming the crust (ca. $50 \mathrm{~nm}$ ). Probably, gaps and slits between the crystals in the crust are seen in porosity studies as micropores.

$\mathrm{pH}$ titration data (Figure 5) reveal that initial silica gel samples in alkaline media display cation exchange functions possessing $2.0 \mathrm{mM} / \mathrm{g}$ of exchangeable protons. Modified silica gels in alkaline media retain this function. In sample A, the amount of exchangeable protons does not change, whereas in sample B it reaches $9.2 \mathrm{mM} / \mathrm{g}$. In acidic media, initial silica gel samples manifest anion exchange function $(2.5 \mathrm{mM} / \mathrm{g})$. According to the literature data [52-54], this is unusual for silica gel and can be explained by the presence of alumina in it. In modified samples, the anion exchange function decreases and becomes equal to $1.0 \mathrm{mM} / \mathrm{g}$, probably reflecting a surface blocking caused by the oxide.

Before adsorption studies with modified silica gels, dissolution of the hematite layer in solutions of various acidity was determined and a special examination of the affinity of initial silica gel and hematite for phosphate ions was performed. The solubility of the coating in solutions of $\mathrm{pH}=4,6$, and 8 after their contact with samples for $24 \mathrm{~h}$ does not depend on $\mathrm{pH}$ and is negligible: less than $1 \%$ of iron oxide deposited onto the silica gel surface passes into the solution. It was found that initial silica gel samples do not adsorb phosphate ions from alkaline media, and adsorption from acidic media appeared insignificantly small. Hematite obtained by means of the citric acid route forms colloidal solutions, and studies of its affinity towards phosphate ions were unsuccessful. However, the literature data obtained with a number of hematites of

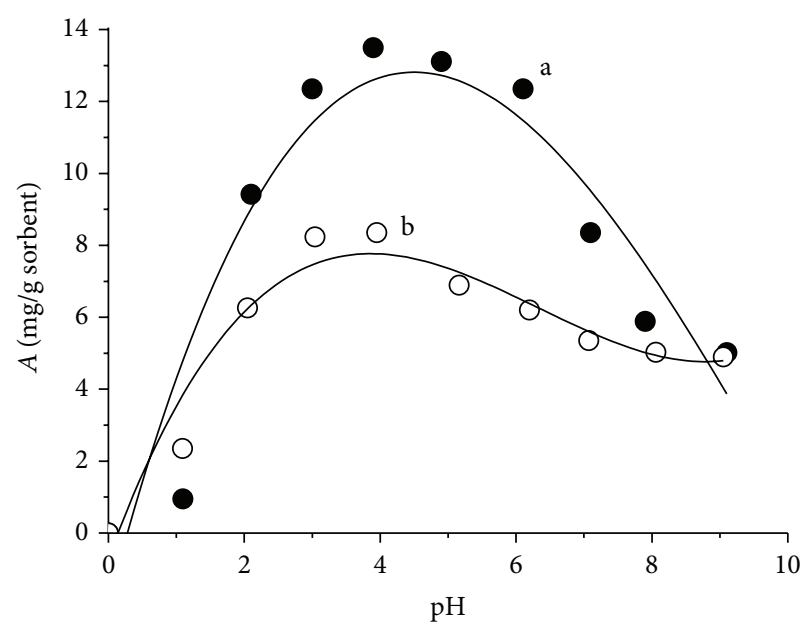

FIGURE 6: Dependence of adsorption capacity on $\mathrm{pH}$ for modified silica gel samples. Sample A (a): $C_{0}=5.6 \mathrm{~g} / \mathrm{L}$ and sample B (b): $C_{0}=$ $5.99 \mathrm{~g} / \mathrm{L}$.

different origin reveal that at $\mathrm{pH} \sim 5-6$, limiting adsorption $\left(A_{\infty}\right)$ of phosphate ions onto natural hematites (14 samples) lies between 0.6 and $11 \mathrm{mg} / \mathrm{g}$ with the mean value of $A_{\infty}$ $=3.5 \mathrm{mg} / \mathrm{g}$ [55]. Similar values for 43 samples of synthetic hematites are $0.4-14 \mathrm{mg} / \mathrm{g}$ with the mean value of $A_{\infty}=$ $5.1 \mathrm{mg} / \mathrm{g}[56]$.

The dependence of phosphate sorption by modified sorbents on the acidity of solutions evidences (Figure 6) that in acidic media sorption is small and the maximum of the phosphate uptake is situated in the $\mathrm{pH}$ region where the initial silica gel shows up no anion exchange properties or behaves as a cation exchanger. At $\mathrm{pH}$ from 2 to 9 , for sample $\mathrm{A}$, the quantity of phosphate adsorbed equals $6-13.5 \mathrm{mg}$ per $1 \mathrm{~g}$ of the sorbent, which amounts at $950-2150 \mathrm{mg}$ of $\mathrm{PO}_{4}{ }^{3-}$ per $1 \mathrm{~g}$ of hematite. For sample B, these values are 5-8 mg/g and 400$650 \mathrm{mg} / \mathrm{g}$.

Based on these data, adsorption isotherms were obtained at $\mathrm{pH}=4$ and 8 (Figure 7). Their treatment was performed using the Langmuir equation

$$
A=\frac{A_{\infty} K C_{\mathrm{eq}}}{1+K C_{\mathrm{eq}}}
$$

where $A$ is the adsorption value in $\mathrm{mg} / \mathrm{g}$ obtained at the equilibrium concentration of the sorbate $C_{\mathrm{eq}}, \mathrm{g} / \mathrm{L}, A_{\infty}$ is the limiting adsorption value in $\mathrm{mg} / \mathrm{g}$, and $K$ is a constant measured in L/g. Respective values of $A_{\infty}$ and $K$ for samples A and $B$ are summarized in Table 2. As expected, limiting values of the phosphate ion adsorption onto hematite supported on silica gel are at least two orders of magnitude greater than those for natural and synthetic hematites $[55,56]$. It should be mentioned, however, that saturation of the sorbent takes place much faster than the Langmuir equation predicts, being especially pronounced in the case of sample $\mathrm{A}$, for which the calculated Langmuir dependencies do not completely match the experimental points (Figure 7). On the one hand, this makes the Langmuir fits tentative; on the other hand, fast saturation of the sorbent may be indicative for mechanisms 
TABLE 2: Parameters of the Langmuir equations and $\mathrm{Fe}^{3+}: \mathrm{PO}_{4}{ }^{3-}$ molar ratio for adsorbates.

\begin{tabular}{|c|c|c|c|c|c|c|}
\hline \multirow[b]{2}{*}{ Sample } & \multicolumn{2}{|c|}{$A_{\infty}, \mathrm{mg} / \mathrm{g}$} & \multirow[b]{2}{*}{$K, \mathrm{~L} / \mathrm{g}$} & \multicolumn{2}{|c|}{$A_{\text {max. }}, \mathrm{mg} / \mathrm{g}$} & \multirow{2}{*}{$\begin{array}{l}\mathrm{Fe}^{3+}: \mathrm{PO}_{4}{ }^{3-} \text { molar ratio } \\
\text { on the surface }\end{array}$} \\
\hline & $\begin{array}{c}\text { Per } 1 \mathrm{~g} \\
\text { of the sorbent }\end{array}$ & $\begin{array}{c}\text { Per } 1 \mathrm{~g} \\
\text { of hematite }\end{array}$ & & $\begin{array}{c}\text { Per } 1 \mathrm{~g} \\
\text { of the sorbent }\end{array}$ & $\begin{array}{c}\text { Per 1g } \\
\text { of hematite }\end{array}$ & \\
\hline \multicolumn{7}{|c|}{$\mathrm{pH}=4$} \\
\hline A & $14.57 \pm 1.03$ & $2345 \pm 166$ & $3.57 \pm 1.28$ & 12.2 & 1964 & $1: 1.66$ \\
\hline $\mathrm{B}$ & $9.28 \pm 0.46$ & $742 \pm 37$ & $0.59 \pm 0.14$ & 8.4 & 672 & $1: 0.56$ \\
\hline \multicolumn{7}{|c|}{$\mathrm{pH}=8$} \\
\hline A & $5.57 \pm 0.37$ & $897 \pm 60$ & $4.13 \pm 1.53$ & 5.2 & 837 & $1: 0.70$ \\
\hline $\mathrm{B}$ & $6.51 \pm 0.28$ & $521 \pm 22$ & $0.19 \pm 0.02$ & 5.2 & 416 & $1: 0.35$ \\
\hline
\end{tabular}

other than adsorption, namely, for precipitation of ferric phosphates.

Knowing the adsorption values attained at the maximal concentrations of solutions and expressed in $\mathrm{mg}$ of $\mathrm{PO}_{4}{ }^{3-}$ per $1 \mathrm{~g}$ of hematite, one can find the maximal $\mathrm{Fe}^{3+}: \mathrm{PO}_{4}{ }^{3-}$ molar ratios on the surface of modified samples (Table 2 ). They are quite close to the $\mathrm{Fe}^{3+}: \mathrm{PO}_{4}{ }^{3-}$ ratios in stoichiometric compounds; therefore, it is reasonable to claim the complete conversion of hematite and the formation of single ferric phosphates (or their mixtures) on the surface of silica gel. It is noticeable that the degree of conversion of hematite to iron phosphates is greater in acidic media and at a lower surface coverage, when hematite crystallites are small and better accessible by adsorbate.

There are two possible explanations of such a behavior of the samples studied. Firstly, some authors have already drawn attention to the existence of common (competitive) and specific (selective) adsorption sites on the surface of hematite crystals [57]. As follows from recent studies [58], such selective sites may be associated with low coordinated $\mathrm{Fe}$ atoms on the $\{104\}$ facets of hematite (reflections from planes parallel to this facet are the most intense in XRD data, Figure 2). Flat hematite crystals forming the developed $\{104\}$ facets, like those discernible for sample A, Figure 4(c), are especially active towards the oxygen atoms of phosphoryl groups [58] and significantly differ from ordinary hematite particles, sample B, Figures 4(d)-4(f), formed by (001) basal planes and (012) side planes [51]. Based on this observation, different affinities of samples A and B towards phosphate ions are due to differences in the morphology of deposited hematite particles.

Secondly, the degree of conversion of $\mathrm{Fe}_{2} \mathrm{O}_{3}$ to a respective phosphate is determined by the rate of diffusion of the $\mathrm{PO}_{4}{ }^{3-}$ ions into the bulk of the oxide crystal. In its turn, the diffusion rate depends on the charge of the crystal surface. The point of zero charge of hematite lies at $\mathrm{pH}=7.85 \pm 1.34$ [52-54]. This means that the formation of $\mathrm{Fe}_{2}\left(\mathrm{HPO}_{4}\right)_{3}$ in acidic media proceeds easily since the surface of hematite at $\mathrm{pH}=4$ is charged positively. On the other hand, the formation of basic phosphates is difficult since at $\mathrm{pH}=8$, the surface of hematite is charged negatively, thus preventing from diffusion of both phosphate and hydroxyl ions. These circumstances may explain the greater degree of conversion of hematite to phosphate at lower $\mathrm{pH}$ of solutions.

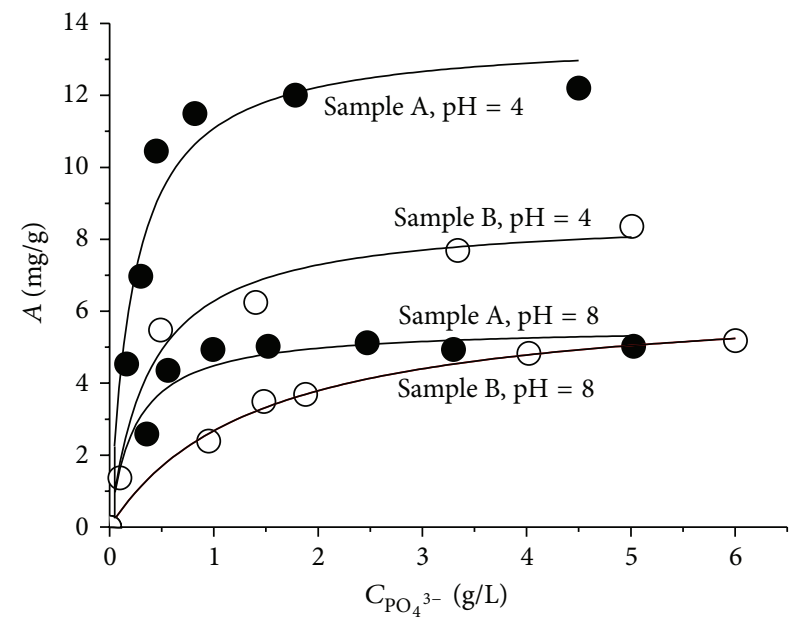

FIgure 7: Phosphate adsorption isotherms at $\mathrm{pH}=4$ and 8 for samples A and B.

Speaking about the dependence of the degree of conversion on acidity, one should bear in mind that in solutions of different $\mathrm{pH}$, different anionic forms of phosphate dominate: $\mathrm{H}_{2} \mathrm{PO}_{4}{ }^{-}$at $\mathrm{pH}=4-5$ and $\mathrm{HPO}_{4}{ }^{2-}$ at $\mathrm{pH}=8.5-9.5$ [59]. However, in systems containing $\mathrm{Fe}^{3+}$ anions, precipitation of salts of different phosphate anions takes place at $\mathrm{pH}$ values much lower (i.e., in more acidic media) than the region of existence of respective anionic forms: for instance, $\mathrm{Fe}_{2}\left(\mathrm{HPO}_{4}\right)_{3}\left(\mathrm{Fe}^{3+}: \mathrm{PO}_{4}{ }^{3-}=1: 1.5\right)$ precipitates at $\mathrm{pH} \sim 2$ [60] and $\mathrm{FePO}_{4}\left(\mathrm{Fe}^{3+}: \mathrm{PO}_{4}{ }^{3-}=1: 1\right)$ at $\mathrm{pH} \sim 6.5$ [61] (Figure 8). Therefore, one can consider that compounds formed on the silica gel surface contain a less acidic anion than that existing in an equilibrium solution. Guidelines for determining the composition of such compounds, in addition to $\mathrm{Fe}_{2}\left(\mathrm{HPO}_{4}\right)_{3}$ and $\mathrm{FePO}_{4}$, can be found in mineralogy.

Among ferric phosphate minerals, in the order of decreasing the $\mathrm{Fe}^{3+}: \mathrm{PO}_{4}{ }^{3-}$ ratio and simultaneous increasing the $\mathrm{Fe}^{3+}: \mathrm{OH}^{-}$ratio, various basic phosphates are known [62] (Table 3). One can guess that for sample A, where the size of hematite particles is small and their inner parts are more accessible, hematite deposited onto the silica gel surface at $\mathrm{pH}$ $=4$ converts mainly to $\mathrm{Fe}_{2}\left(\mathrm{HPO}_{4}\right)_{3}$ and at $\mathrm{pH}=8$ to tinticite $\mathrm{Fe}_{4}\left(\mathrm{HPO}_{4}\right)_{3}(\mathrm{OH})_{3} \cdot 5 \mathrm{H}_{2} \mathrm{O}$, ferristrunzite $\mathrm{Fe}_{3}\left(\mathrm{PO}_{4}\right)_{2}(\mathrm{OH})_{3}$. 
TABLE 3: Natural ferric phosphates [27] ordered according to $\mathrm{Fe}^{3+}: \mathrm{PO}_{4}{ }^{3-}: \mathrm{OH}^{-}$ratio.

\begin{tabular}{lcc}
\hline $\mathrm{Fe}^{3+}: \mathrm{PO}_{4}{ }^{3-}: \mathrm{OH}^{-}$ratio & Chemical formula & Name \\
\hline $1: 0.75: 0.75$ & $\mathrm{Fe}_{4}\left(\mathrm{PO}_{4}\right)_{3}(\mathrm{OH})_{3} \cdot 5 \mathrm{H}_{2} \mathrm{O}$ & Tinticite \\
$1: 0.66: 1$ & $\mathrm{Fe}_{3}\left(\mathrm{PO}_{4}\right)_{2}(\mathrm{OH})_{3} \cdot 5 \mathrm{H}_{2} \mathrm{O}$ & Ferristrunzite (or allanpringite) \\
$1: 0.66: 1.33$ & $\mathrm{NaFe}_{3}\left(\mathrm{PO}_{4}\right)_{2}(\mathrm{OH})_{4} \cdot 2 \mathrm{H}_{2} \mathrm{O}$ & Cyrilovite \\
$1: 0.5: 1.5$ & $\mathrm{Fe}_{4}\left(\mathrm{PO}_{4}\right)_{2}(\mathrm{OH})_{6} \cdot 4-6 \mathrm{H}_{2} \mathrm{O}$ & Delvauxite \\
\hline
\end{tabular}

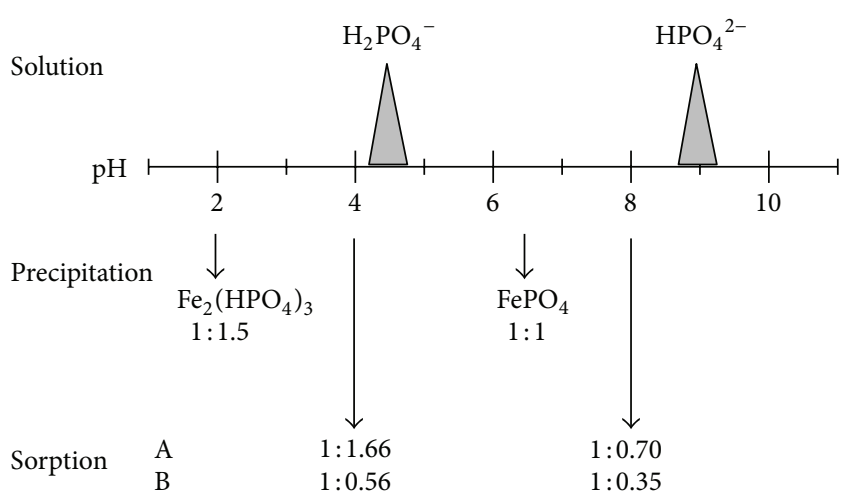

FIGURE 8: pH influence on dominance of anionic forms of phosphate in solutions, precipitation of ferric phosphates, and $\mathrm{Fe}^{3+}: \mathrm{PO}_{4}{ }^{3-}$ ratio in phosphates formed on the silica gel surface.

$5 \mathrm{H}_{2} \mathrm{O}$, or their mixture. For sample $\mathrm{B}$ with greater hematite particles, the composition of compounds formed is probably the same, and the lowering of the $\mathrm{Fe}^{3+}: \mathrm{PO}_{4}{ }^{3-}$ ratio is caused by the presence of some excess hematite remaining due to low accessibility of its bulk.

\section{Conclusions}

In this paper, an attempt to deposit a nanolayer of iron oxide onto the surface of silica gel has been performed, and the ability of this deposit to complete conversion to stoichiometric iron phosphates in the course of adsorption from aqueous solutions has been examined. Modification of silica gel surface by iron oxide in the quantity of 0.62 and 1.25 mass \% has been carried out by means of a citric acid aided method. It has been found that the covering layer consists of hematite.

The morphology of the samples obtained has been studied using low temperature desorption of nitrogen and scanning electron microscopy. As follows from micrographs, hematite covers just the apparent surface of silica gel and does not penetrate its pores. At a low coverage, the coating is represented by flat particles of an indefinite shape and the size of approximately $100 \mathrm{~nm}$. At a high coverage, big crystals of $800 \mathrm{~nm}$ height and $400 \mathrm{~nm}$ thickness are growing on the surface of silica gel.

These differences in morphology determine the ability of hematite layer to adsorb phosphates from aqueous solutions. As expected, all samples studied are able to be almost completely converted to iron phosphates. On the other hand, the degree of conversion of hematite to iron phosphate appears greater (i) in acidic media than in neutral solutions and (ii) at a lower coverage than at a higher one, and these circumstances require explanations. The $\mathrm{pH}$ dependence of the degree of conversion can be described in terms of electrostatics. The role of coverage can be understood accounting for the shape and size of hematite crystals. Different habit of the crystals leads to different affinity of their facets towards phosphate ions. The bulk of bigger crystals formed at a high coverage is less accessible to phosphate ions.

In acidic media $(\mathrm{pH}=4)$, hematite deposited onto the silica gel surface converts mainly to $\mathrm{Fe}_{2}\left(\mathrm{PO}_{4}\right)_{3}$ and in almost neutral solutions $(\mathrm{pH}=8)$, to basic phosphates, like tinticite $\mathrm{Fe}_{4}\left(\mathrm{PO}_{4}\right)_{3}(\mathrm{OH})_{3} \cdot 5 \mathrm{H}_{2} \mathrm{O}$, ferristrunzite $\mathrm{Fe}_{3}\left(\mathrm{PO}_{4}\right)_{2}(\mathrm{OH})_{3}$. $5 \mathrm{H}_{2} \mathrm{O}$, or their mixture. However, this conclusion should be considered tentative, and its confirmation will require some additional investigations of adsorbents and adsorbates by means of vibrational spectroscopy $[63,64]$ that are now in progress.

To summarize we conclude that, in line with $[4-6,9,11-$ 14], the adsorption affinity nanosized adsorbents increases as the particle size decreases; furthermore, the adsorption of phosphate ion onto hematite deposited onto the silica gel surface leads to the complete conversion to stoichiometric iron phosphates.

\section{References}

[1] N. Savage and M. S. Diallo, "Nanomaterials and water purification: opportunities and challenges," Journal of Nanoparticle Research, vol. 7, no. 4-5, pp. 331-342, 2005.

[2] M. M. Khin, A. S. Nair, V. J. Babu, R. Murugan, and S. Ramakrishna, "A review on nanomaterials for environmental remediation," Energy and Environmental Science, vol. 5, no. 8, pp. 8075-8109, 2012.

[3] V. H. Grassian, "When size really matters: size-dependent properties and surface chemistry of metal and metal oxide nanoparticles in gas and liquid phase environments," Journal of Physical Chemistry C, vol. 112, no. 47, pp. 18303-18313, 2008.

[4] G. A. Waychunas, C. S. Kim, and J. F. Banfield, "Nanoparticulate iron oxide minerals in soils and sediments: unique properties and contaminant scavenging mechanisms," Journal of Nanoparticle Research, vol. 7, no. 4-5, pp. 409-433, 2005.

[5] S. Yean, L. Cong, C. T. Yavuz et al., "Effect of magnetite particle size on adsorption and desorption of arsenite and arsenate," Journal of Materials Research, vol. 20, no. 12, pp. 3255-3264, 2005.

[6] H. Zeng, A. Singh, S. Basak et al., "Nanoscale size effects on uranium(VI) adsorption to hematite," Environmental Science and Technology, vol. 43, no. 5, pp. 1373-1378, 2009. 
[7] D. M. Cwiertny, R. M. Handler, M. V. Schaefer, V. H. Grassian, and M. M. Scherer, "Interpreting nanoscale size-effects in aggregated Fe-oxide suspensions: reaction of Fe(II) with Goethite," Geochimica et Cosmochimica Acta, vol. 72, no. 5, pp. 1365-1380, 2008.

[8] Y. Gao, R. Wahi, A. T. Kan, J. C. Falkner, V. L. Colvin, and M. B. Tomson, "Adsorption of cadmium on anatase nanoparticleseffect of crystal size and pH," Langmuir, vol. 20, no. 22, pp. 95859593, 2004

[9] D. E. Giammar, C. J. Maus, and L. Xie, "Effects of particle size and crystalline phase on lead adsorption to titanium dioxide nanoparticles," Environmental Engineering Science, vol. 24, no. 1, pp. 85-95, 2007.

[10] J. M. Pettibone, D. M. Cwiertny, M. Scherer, and V. H. Grassian, "Adsorption of organic acids on $\mathrm{TiO}_{2}$ nanoparticles: effects of $\mathrm{pH}$, nanoparticle size, and nanoparticle aggregation," Langmuir, vol. 24 , no. 13 , pp. 6659-6667, 2008.

[11] K. E. Engates and H. J. Shipley, "Adsorption of Pb, Cd, Cu, Zn, and $\mathrm{Ni}$ to titanium dioxide nanoparticles: effect of particle size, solid concentration, and exhaustion," Environmental Science and Pollution Research, vol. 18, no. 3, pp. 386-395, 2011.

[12] M. J. Comarmond, T. E. Payne, J. J. Harrison et al., "Uranium sorption on various forms of titanium dioxide-influence of surface area, surface charge, and impurities," Environmental Science and Technology, vol. 45, no. 13, pp. 5536-5542, 2011.

[13] N. Bektaş, B. A. Ağim, and S. Kara, "Kinetic and equilibrium studies in removing lead ions from aqueous solutions by natural sepiolite," Journal of Hazardous Materials, vol. 112, no. 1-2, pp. 115-122, 2004.

[14] R. Donat, A. Akdogan, E. Erdem, and H. Cetisli, "Thermodynamics of $\mathrm{Pb}^{2+}$ and $\mathrm{Ni}^{2+}$ adsorption onto natural bentonite from aqueous solutions," Journal of Colloid and Interface Science, vol. 286, no. 1, pp. 43-52, 2005.

[15] L. Cumbal, J. Greenleaf, D. Leun, and A. K. SenGupta, "Polymer supported inorganic nanoparticles: characterization and environmental applications," Reactive and Functional Polymers, vol. 54, no. 1-3, pp. 167-180, 2003.

[16] B. Pan, B. Pan, W. Zhang, L. Lv, Q. Zhang, and S. Zheng, "Development of polymeric and polymer-based hybrid adsorbents for pollutants removal from waters," Chemical Engineering Journal, vol. 151, no. 1-3, pp. 19-29, 2009.

[17] O. Hernandez-Ramirez and S. M. Holmes, "Novel and modified materials for wastewater treatment applications," Journal of Materials Chemistry, vol. 18, no. 24, pp. 2751-2761, 2008.

[18] S. Sarkar, P. K. Chatterjee, L. H. Cumbal, and A. K. SenGupta, "Hybrid ion exchanger supported nanocomposites: sorption and sensing for environmental applications," Chemical Engineering Journal, vol. 166, no. 3, pp. 923-931, 2011.

[19] D. Mohan and C. U. Pittman Jr., "Arsenic removal from water/wastewater using adsorbents-a critical review," Journal of Hazardous Materials, vol. 142, no. 1-2, pp. 1-53, 2007.

[20] L. E. de-Bashan and Y. Bashan, "Recent advances in removing phosphorus from wastewater and its future use as fertilizer (1997-2003)," Water Research, vol. 38, no. 19, pp. 4222-4246, 2004.

[21] N. Boujelben, J. Bouzid, Z. Elouear, M. Feki, F. Jamoussi, and A. Montiel, "Phosphorus removal from aqueous solution using iron coated natural and engineered sorbents," Journal of Hazardous Materials, vol. 151, no. 1, pp. 103-110, 2008.

[22] M. J. DeMarco, A. K. SenGupta, and J. E. Greenleaf, "Arsenic removal using a polymeric/inorganic hybrid sorbent," Water Research, vol. 37, no. 1, pp. 164-176, 2003.
[23] H. Ma, Z. Zhu, L. Dong, Y. Qiu, and E. J. Zhao, "Removal of arsenate from aqueous solution by manganese and iron (hydr)oxides coated resin," Separation Science and Technology, vol. 46, no. 1, pp. 130-136, 2011.

[24] R. C. Vaishya and S. K. Gupta, "Modeling arsenic(V) removal from water by sulfate modified iron-oxide coated sand (SMIOCS)," Separation Science and Technology, vol. 39, no. 3, pp. 645-666, 2004.

[25] S. Kundu and A. K. Gupta, "Sorption kinetics of As(V) with iron-oxide-coated cement-a new adsorbent and its application in the removal of arsenic from real-life groundwater samples," Journal of Environmental Science and Health A, vol. 40, no. 12, pp. 2227-2246, 2005.

[26] Z. Gu, J. Fang, and B. Deng, "Preparation and evaluation of GAC-based iron-containing adsorbents for arsenic removal," Environmental Science and Technology, vol. 39, no. 10, pp. 38333843, 2005.

[27] K. S. W. Sing, D. H. Everett, R. A. W. Haul et al., "Reporting physisorption data for gas/solid systems with special reference to the determination of surface area and porosity," Pure and Applied Chemistry, vol. 57, no. 4, pp. 603-619, 1985.

[28] R. K. Iler, The Chemistry of Silica, John Wiley \& Sons, New York, NY, USA, 1979.

[29] P. K. Jal, S. Patel, and B. K. Mishra, "Chemical modification of silica surface by immobilization of functional groups for extractive concentration of metal ions," Talanta, vol. 62 , no. 5 , pp. 1005-1028, 2004.

[30] G. V. Lisichkin, Chemistry of Grafted Surface Compounds, Fizmatlit, Moscow, Russia, 2003.

[31] K. Ohta, H. Morikawa, K. Tanaka, Y. Uwamino, M. Furukawa, and M. Sando, "Ion-chromatographic behavior of alkali metal cations and ammonium ion on zirconium-adsorbing silica gel," Journal of Chromatography A, vol. 884, no. 1-2, pp. 123-130, 2000.

[32] V. M. Bogatyrov, M. V. Borysenko, I. V. Dubrovin, M. V. Abramov, M. V. Galaburda, and P. P. Gorbyk, "Synthesis and properties of magnetosensitive nanocomposites based on iron oxide deposited on fumed silica," in Nanomaterials and Supramolecular Structures, A. P. Shpak and P. P. Gorbyk, Eds., pp. 159-168, Springer, Dordrecht, The Netherlands, 2009.

[33] P. N. Nesterenko, E. P. Nesterenko, and A. V. Ivanov, "Modification of silica surface with alumina," Vestnik Moskovskogo Universiteta 2, vol. 42, no. 2, pp. 106-108, 2001.

[34] S. A. Kirillov, I. V. Romanova, and I. A. Farbun, "Synthesis of mixed oxides using polybasic carboxylic hydroxy- and aminoacid routes: problems and prospects," in New Carbon Based Materials for Electrochemical Energy Storage Systems, I. V. Barsukov, C.S. Johnson, J.E. Doninger, and V.Z. Barsukov, Eds., pp. 495-504, Springer, Dordrecht, The Netherlands, 2006.

[35] I. V. Romanova, I. A. Farbun, T. E. Terikovskaya, D. I. Dzanashvili, and S. A. Kirillov, "Complex formation in the course of synthesis of zinc oxide from citrate solutions," Russian Journal of Applied Chemistry, vol. 80, no. 11, pp. 1798-1803, 2007.

[36] I. V. Romanova, I. A. Farbun, S. A. Khainakov, S. A. Kirillov, and V. A. Zazhigalov, "Studies of catalytic properties of materials based on transition metal oxides and ceria," Dopovidi Natsional'Noi Akademii Nauk Ukrainy, pp. 153-159, 2008 (Russian), http://www.nbuv.gov.ua/portal/all/reports/2008-10/08-10-28 .pdf.

[37] I. A. Farbun, I. V. Romanova, and S. A. Kirillov, "Optimal design of powdered nanosized oxides of high surface area and porosity 
using a citric acid aided route, with special reference to $\mathrm{ZnO}$," Journal of Sol-Gel Science and Technology, 2013.

[38] GOST, 3956. 76, Silica gel for industrial use, Specifications, 1976.

[39] GOST, 22552. 2-93, Quartz sand, ground sandstone, quartzite and veiny quartz for glass industry, Methods for determination of ferric oxide, 1993.

[40] GOST, 22552. 3-93, Quartz sand, ground sandstone, quartzite and veiny quartz for glass industry, Methods for determination of aluminium oxide, 1993.

[41] GOST, 13078-81, Sodium silicate solute, Specifications, 1981.

[42] ASTM C146-94a, Standard test methods for chemical analysis of glass sand, 2009.

[43] ISO, 6332-1988, Water quality, Determination of iron, Spectrometric method using 1,10 phenantroline, 1988.

[44] GOST, 18309-72, Drinking water, Method for determination of polyphosphate content, 1972.

[45] P. S. Sidhu, "Transformation of trace element-substituted maghemite to hematite," Clays and Clay Minerals, vol. 36, no. 1, pp. 31-38, 1988.

[46] N. Randrianantoandro, A. M. Mercier, M. Hervieu, and J. M. Grenèche, "Direct phase transformation from hematite to maghemite during high energy ball milling," Materials Letters, vol. 47, no. 3, pp. 150-158, 2001.

[47] A. L. Patterson, "The scherrer formula for X-ray particle size determination," Physical Review, vol. 56, no. 10, pp. 978-982, 1939.

[48] K. Kandori, N. Yamamoto, A. Yasukawa, and T. Ishikawa, "Preparation and characterization of disk-shaped hematite particles by a forced hydrolysis reaction in the presence of polyvinyl alcohol," Physical Chemistry Chemical Physics, vol. 4, no. 24, pp. 6116-6122, 2002.

[49] R. L. Blake, R. E. Hessevick, T. Zoltai, and W. Finger, "Refinement of the hematite structure," The American Mineralogist, vol. 51, pp. 123-129, 1966.

[50] M. Popovici, C. Savii, C. Enache, D. Niziiansky, I. Subrt, and E. Vecemikova, "Sol-gel derived iron oxide-silica nanocomposites, starting from iron chloride and iron nitrate," Journal of Optoelectronics and Advanced Materials, vol. 7, no. 5, pp. 2753-2762, 2005.

[51] T. Sugimoto, S. Waki, H. Itoh, and A. Muramatsu, "Preparation of monodisperse platelet-type hematite particles from a highly condensed $\beta$-FeOOH suspension," Colloids and Surfaces A, vol. 109, pp. 155-165, 1996.

[52] M. Kosmulski, "The pH-dependent surface charging and the points of zero charge," Journal of Colloid and Interface Science, vol. 253, no. 1, pp. 77-87, 2002.

[53] M. Kosmulski, "pH-dependent surface charging and points of zero charge II. Update," Journal of Colloid and Interface Science, vol. 275, no. 1, pp. 214-224, 2004.

[54] M. Kosmulski, "pH-dependent surface charging and points of zero charge. III. Update," Journal of Colloid and Interface Science, vol. 298, no. 2, pp. 730-741, 2006.

[55] J. Torrent, U. Schwertmann, and V. Barrón, "Phosphate sorption by natural hematites," European Journal of Soil Science, vol. 45, no. 1, pp. 45-51, 1994.

[56] V. Barrón, M. Herruzo, and J. Torrent, "Phosphate adsorption by aluminous hematites of different shapes," Soil Science Society of America Journal, vol. 52, no. 3, pp. 647-651, 1988.

[57] A. L. Gimsing and O. K. Borggaard, "Phosphate and glyphosate adsorption by hematite and ferrihydrite and comparison with other variable-charge minerals," Clays and Clay Minerals, vol. 55, no. 1, pp. 108-114, 2007.

[58] P. Mäkie, G. Westin, P. Persson, and L. Österlund, "Adsorption of trimethyl phosphate on maghemite, hematite, and goethite nanoparticles," Journal of Physical Chemistry A, vol. 115, no. 32, pp. 8948-8959, 2011.

[59] A. Albert and E. Sergeant, Ionization Constant of Acids and Bases, Methuen, London, UK, 1962.

[60] E. Pierri and E. Dalas, "The precipitation of ferric phosphate on porous polymer," Colloids and Surfaces A, vol.139, no. 3, pp. 335340, 1998.

[61] B. Boonchom and S. Puttawong, "Thermodynamics and kinetics of the dehydration reaction of $\mathrm{FePO}_{4} \cdot 2 \mathrm{H}_{2} \mathrm{O}$," Physica $B$, vol. 405, no. 9, pp. 2350-2355, 2010.

[62] J. W. Anthony, R. A. Bideaux, K. W. Bladh, and M. C. Nichols, Handbook of Mineralogy, Mineralogical Society of America, Chantilly, Va, USA, http://www.handbookofmineralogy.org.

[63] P. Persson, N. Nilsson, and S. Sjöberg, "Structure and bonding of orthophosphate ions at the iron oxide-aqueous interface," Journal of Colloid and Interface Science, vol. 177, no. 1, pp. 263275, 1996.

[64] E. J. Elzinga and D. L. Sparks, "Phosphate adsorption onto hematite: an in situ ATR-FTIR investigation of the effects of $\mathrm{pH}$ and loading level on the mode of phosphate surface complexation," Journal of Colloid and Interface Science, vol. 308, no. 1, pp. 53-70, 2007. 

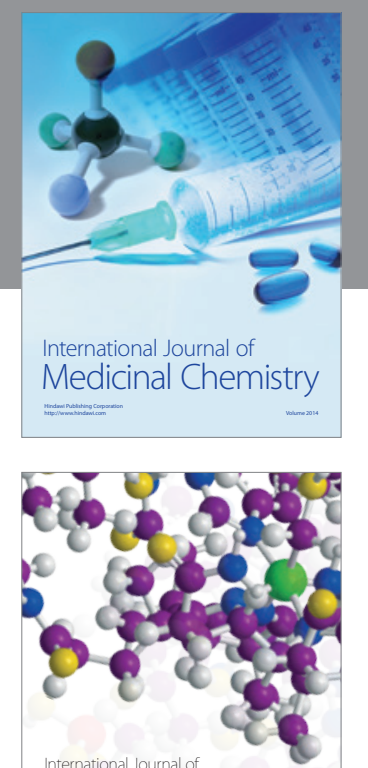

\section{Carbohydrate} Chemistry

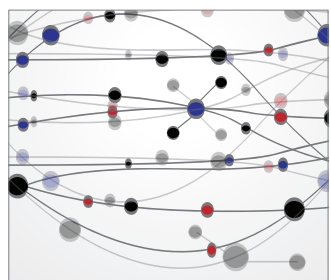

The Scientific World Journal
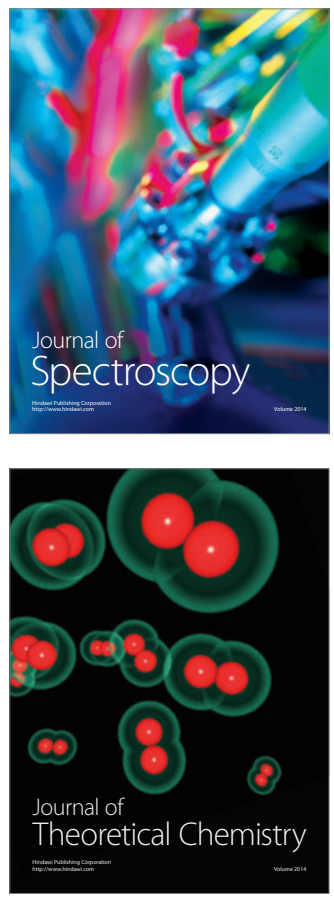
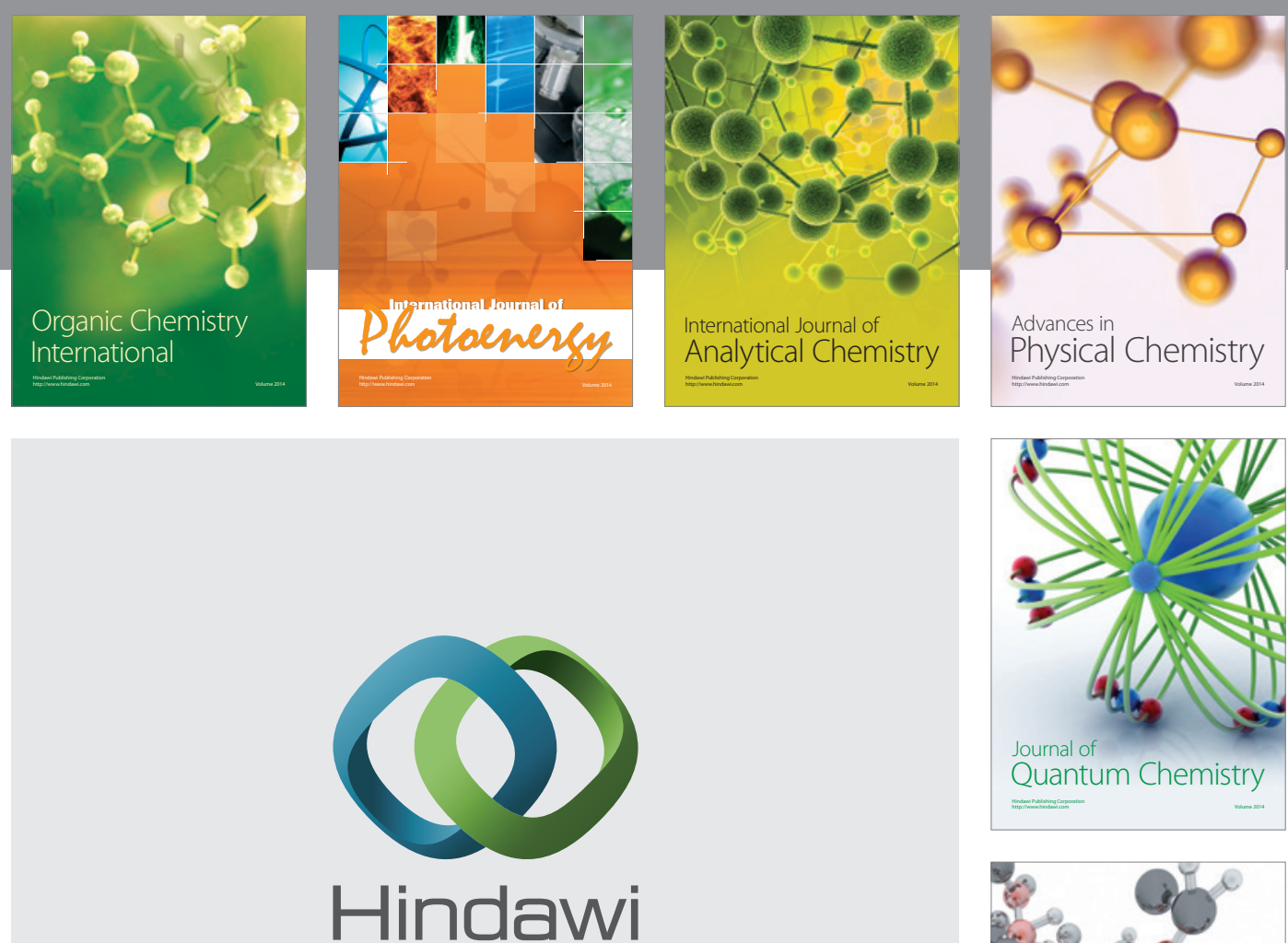

Submit your manuscripts at

http://www.hindawi.com

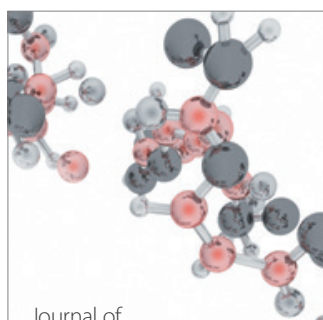

Analytical Methods

in Chemistry

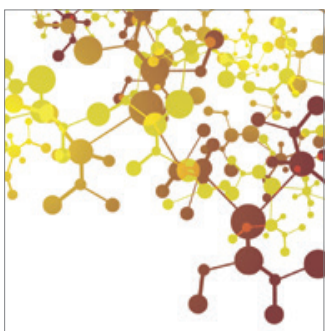

Journal of

Applied Chemistry

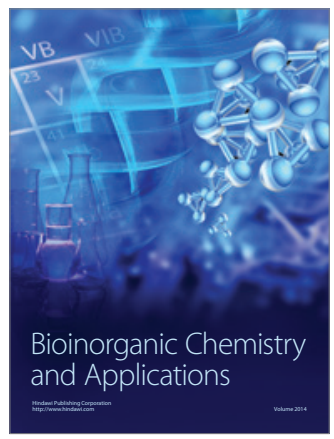

Inorganic Chemistry
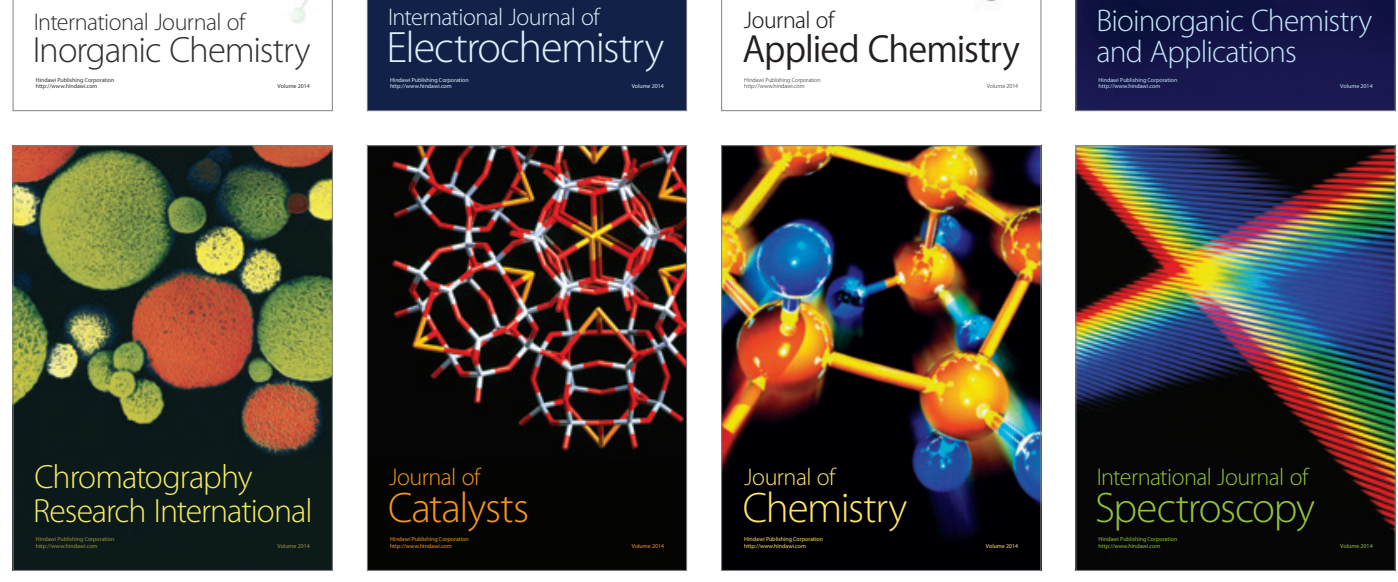